$$
\text { DOE/NV/11432--T7 }
$$

Control \#1036

Thomas A. Wilczek

Reynolds Electrical \& Engineering Company, Inc. M/S 428, Post Office Box 98521

Las Vegas, NV 89193-8521

(P) (702) 295-5396/ (F) (702) 295-0289

\title{
Pollution Prevention in Environmental Restoration Projects: Communication, Innovation, and Implementation
}

\section{Overview}

With the change in U.S. Department of Energy's (DOE) primary mission from weapons production to complex clean-up, there is an increased emphasis to utilize proven tools and techniques that, when modified, will assist in this massive remediation effort. Tools and techniques which increase process efficiency while minimizing costs are highly attractive. The introduction of formalized Pollution Prevention (P2) practices into the DOE Environmental Restoration (ER) program should be encouraged due to the measurable degree of success that $\mathrm{P} 2$ has obtained in DOE process operations. Most notably, the integration of Pollution Prevention Opportunity Assessments (PPOAs) into the ER process is highly recommended for three reasons: waste stream generation volumes will be minimized; the results of $\mathbf{P} 2$ implementation will be properly measured, quantified, and documented for use on other projects; and negative impacts to human health and the environment will be lessened.

The application of $\mathrm{P} 2$ principles is encouraged as a Best Management Practice (BMP), in addition to minimizing waste generation to achieve DOE waste reduction goals. The challenge is how to apply P2 practices to ER projects and obtain quantifiable waste reductions.

\section{Pollution Prevention/Environmental Restoration Comparison}

P2 is recognized as a process-driven practice, applicable to cyclic operations within DOE. Waste Minimization successes are documented because inputs and outputs can be quantified, and reductions in process material usage and/or waste stream generation can be measured. An ER project, however, is a dynamic series of activities operating within a defined schedule. The final objective is successful stabilization and/or remediation of the contaminated area. In activities where much about the site condition is unknown, it is not uncommon for the baseline project cost and schedule to be revised as additional site data are obtained through the characterization process. Unlike cyclic production operations, ER projects are modified and adapted to meet the changing site conditions.

\section{Case Study}

The innovative solution described in this narrative was developed in response to sampling difficulties encountered in the DOE/Nevada Operations Office Environmental Restoration ALandoned Underground Storage Tank (UST) Remediation Program. ER personnel reacted to an unforeseen condition in which current tools and technologies were 


\section{DISCLAIMER}

Portions of this document may be illegible in electronic image products. Images are produced from the best available original document. 


\section{DISCLAIMER}

This report was prepared as an account of work sponsored by an agency of the United States Government. Neither the United States Government nor any agency thereof, nor any of their employees, makes any warranty, express or implied, or assumes any legal liability or responsibility for the accuracy, completeness, or usefulness of any information, apparatus, product, or process disclosed, or represents that its use would not infringe privately owned rights. Reference herein to any specific commercial product, process, or service by trade name, trademark, manufacturer, or otherwise does not necessarily constitute or imply its endorsement, recommendation, or favoring by the United States Government or any agency thereof. The views and opinions of authors expressed herein do not necessarily state or reflect those of the United States Government or any agency thereof. 
Thomas A. Wilczek

Reynolds Electrical \& Engineering Company, Inc.

M/S 428, Post Office Box 98521

Las Vegas, NV 89193-8521

(P) (702) 295-5396/ (F) (702) 295-0289

both inadequate and expensive. ER personnel had not been introduced to formalized P2 practices, such as PPOAs, and yet were able to minimize waste stream generation, reduce project costs, and lessen potential impacts to the environment. As one of DOE's environmental stakeholders, ER personnel attempt to incorporate P2 on an unstructured basis into their programs through the minimization of waste stream volumes and disposal costs during project implementation. The case study describes a scenario where a P2 success was achieved because ER personnel identified it as a BMP, even though a formal P2 process was not implemented for the project.

\section{ER Project Description}

In 1993, initial tank content characterization efforts began on four abandoned USTs located in Area 12 of the Nevada Test Site (NTS). The four tanks were identified as UST numbers 12-8-1\&2 (Area 12 Construction Shop) and 12-9-1\&2 (Area 12 Medical Facility). Each of the four, eight-foot diameter tanks had a 10,000-gallon capacity, and were originally utilized as gasoline and diesel storage tanks for two vehicle fueling stations. A records search indicated the tanks had been abandoned when the fueling stations had been removed in the late 1960s. No documentation was found as to the disposition of the USTs contents after fueling station removal. During the initial characterization effort, it was discovered that each tank was approximately 90-100 percent full of unknown multiphasic substances. It was determined that the upper phase was residual hydrocarbon liquids, and the bottom phase was drilling mud. Instead of setting up and hardening, the drilling mud existed in varying levels of viscosity. This condition existed because the USTs were sealed and covered under approximately three feet of topsoil, and for over twenty years air could not circulate into the tanks and under the hydrocarbon phase to cure the mud.

The hydrocarbon phase in each UST ranged from 4 to 36 inches in depth. The hydrocarbon layers in each UST were characterized by sampling with a 42 -inch, glass composite liquid waste sampler (coliwasa) sampling tool. The coliwasa is a clear, hollow tube which is open at both ends. The sampling end tapers inwards slightly. While obtaining a sample, the technician manipulates a glass rod with a small grommet attached to the end of it. When a sufficient amount of material is collected, the technician plunges the rod through the inside of the tube, and utilizes the grommet to seal the bottom opening. The coliwasa is then retrieved by the technician. At the NTS, the standard battery of analytical tests for UST content sampling was:

- Volatile Organic Compounds (VOCs), EPA Method 8240

- Semi-Volatile Organic Compounds, EPA Method 8270

Pollution Prevention in Environmental Restoration Projects: 
Control \#1036

Thomas A. Wilczek

Reynolds Electrical \& Engineering Company, Inc.

M/S 428, Post Office Box 98521

Las Vegas, NV 89193-8521

(P) (702) 295-5396/ (F) (702) 295-0289

- Total Metals, EPA Method 6010

- Polychlorinated Biphenyls, EPA Method 8080

- Total Petroleum Hydrocarbons, EPA Method 8015, Modified

- $\quad \mathrm{pH}, \mathrm{EPA}$ Method 9045 (applicable when material is not an organic)

- Flash Point, EPA Method 1010

- Gamma Spectroscopy, Reynolds Electrical \& Engineering Company, Inc. (REECo), counting and instrument procedure

After characterization, the hydrocarbons were removed from each UST and disposed of accordingly. Care was taken not to insert the coliwasa into the mud during the sampling effort because of the potential to cross-contaminate the mud with a yet uncharacterized hydrocarbon.

After the hydrocarbon phase was removed, each UST contained approximately 4-7 feet of drilling mud. Since the coliwasa sampling tools utilized at the NTS are only 42 inches long, they could not reach to the bottom of the eight-foot diameter tanks, and therefore could not be used to obtain a representative sample. Also, the coliwasas are constructed of glass, and would break when stuck into the denser layers of the drilling mud.

Sludge sampling tools made from acrylics are available from market sources. After evaluation by the project team, they were not used because: it was determined by the REECo Analytical Services Department that acrylic was not a preferred material for obtaining samples for VOC analysis; the samplers were costly to purchase; and, the samplers would have to be decontaminated after each use. Decontamination costs include the material costs for four 55gallon drums to collect the rinseate from sampling each tank, analytical costs for sampling and characterizing the rinseate, disposal costs for the rinseate, and associated labor costs for sampling, decontamination, and rinseate drum disposal. These costs are in addition to the management costs incurred when generating a waste stream. The total cost to implement this option was estimated at $\$ 20,035$ (FY94 baseline).

ER personnel determined that the current available technology was inadequate and not cost-effective, and if utilized would generate a minimum of 40 gallons of potentially hazardous waste which would have to be properly characterized and disposed of. There was also the unnecessary risk of introducing uncharacterized substances into the environment through the transfer of the material from the USTs into the drums. This option was unacceptable to ER personnel, and it was decided that an innovative approach would need to be developed with on-site resources. It was the intention of the ER personnel to develop and implemerit effective process modifications which meet the intent of the state and federal regulations, and DOE orders; and by doing so reduce costs, increase productivity, eliminate 
Control \#1036

Thomas A. Wilczek

Reynolds Electrical \& Engineering Company, Inc.

$\mathrm{M} / \mathrm{S} 428$, Post Office Box 98521

Las Vegas, NV 89193-8521

(P) (702) 295-5396/ (F) (702) 295-0289

the generation of a potentially hazardous waste stream, and minimize the potential risk of environmental impacts.

\section{Sampling Tool Development}

Since no sampling technology was currently available on the market to meet ER personnel needs, an effective and inexpensive technology was developed for in-house implementation. After consultations with industry professionals and personnel from Lawrence Livermore National Laboratory, it was determined that commercial-grade copper pipe was an acceptable material to construct sampling tools. The copper pipe had an internal diameter of approximately 1.5 inches. A copper check valve was constructed to fit in the end of the 10foot long copper pipe. The check valve used a common glass marble to hold the mud sample in place while it was being withdrawn from the tank. The tool was designed so that when it was inserted into the UST, the dense drilling mud would push the marble up and flow into the pipe. When sufficient sample quantity had flowed into the pipe, the motion of pulling up the pipe caused the marble to descend and block the bottom opening, preventing any of the mud from escaping. A common laboratory glassware detergent was used to clean the sampling tools before their utilization. The in-house sampling tool was preferable for a number of reasons:

- The copper pipe could be utilized to obtain samples for all of the required analysis. It is a common metal which is widely utilized and very inexpensive. As long as the drilling mud was not highly acidic, none of the trace metals in the copper alloy would leach out into the sample. Commonly utilized drilling mud is not acidic, however, in this case it was unknown whether other substances were combined with the mud when it was introduced into the tanks. To confirm that the drilling mud did not exhibit low $\mathrm{pH}$, it was field tested before sampling, and determined to have an acceptable $\mathrm{pH}$ of 6 .

- It was determined that if the sampling tool could be inserted back into the tank after sampling, then no decontamination would be necessary. Guidance from the REECo Environmental Compliance Office stated that there was no known state or federal regulation preventing the introduction of the tool back into the tanks for storage purposes while waiting for sampling results. The extracted mud samples were collected and shipped to the laboratory for analysis. The sampling tools were safely stored and sealed in the tanks until after sampling results were received. The generation and management of suspected prohibited materials was avoided. 
Control \#1036

Thomas A. Wilczek

Reynolds Electrical \& Engineering Company, Inc.

M/S 428, Post Office Box 98521

Las Vegas, NV 89193-8521

(P) (702) 295-5396/ (F) (702) 295-0289

- Regulatory oversight personnel from the State of Nevada Division of Environmental Protection, Bureau of Federal Facilities, concurred with the implementation of the innovative sampling tool at the UST sites.

- The tools were inexpensive to construct. R\&D labor costs for development were a onetime cost of $\$ 2000$. Costs for material and construction of each tool was $\$ 40$. Ten units were produced at a total cost of $\$ 400$.

- Through this process modification, generation of decontamination rinseate and use of expensive sampling equipment was avoided. Overall project costs were reduced.

\section{Effectiveness}

The sampling tools were utilized at the Area 12 UST sites on January 11 and 12, 1994. Seven samples were successfully obtained from the entire strata of drilling mud from each end of the four tanks, and in sufficient quantities for the requested analyses. A planned eighth sample could not be obtained due to the lack of sufficient drilling mud at the east end of UST 12-9-2. After sampling, each copper pipe was reinserted back into the respective tank opening, and the opening sealed. The sampling tools did not generate additional residual waste. After the characterization of the drilling mud, the tools were removed and decontaminated for future use.

\section{Benefits}

Implementation of this sampling tool for this phase of the project generated considerable cost savings in additional sampling and characterization costs. Utilization of this process modification avoided the material costs for eight acrylic sampling tools, four 55gallon drums to collect the rinseate, and analytical costs for sampling and characterizing the rinseate. The costs savings to the FY94 ER Abandoned UST Remediation program was $\$ 17,635$. The use of the sampling tool also minimized waste stream generation, and in the state of Nevada, increased the DOE's credibility as responsible stewards of the environment. Based upon the success of the sampling tool, utilization of this technology for future sampling activities shall continue to be pursued and implemented. The technology is easily modified for application across the DOE complex.

\section{Conclusion}

In the case study, waste minimization was achieved because it demonstrated a BMP by the project personnel. ER personnel proved to be an excellent resource for development and implementation of the sampling tool, and would embrace additional opportunities to minimize primary and secondary waste stream generation during site remediation. Incorporation of 
Control \#1036

Thomas A. Wilczek

Reynolds Electrical \& Engineering Company, Inc.

M/S 428, Post Office Box 98521

Las Vegas, NV 89193-8521

(P) (702) 295-5396/ (F) (702) 295-0289

formalized P2 practices, such as Pollution Prevention Opportunity Assessments, into ER projects as a BMP will strengthen participant commitment across DOE and generate additional programmatic successes.

Acknowledgements

The authors wishes to acknowledge: the invaluable teamwork provided by REECo ER Section personnel Steven A. Bobo and David D. Madsen; and the guidance provided by Cynthia L. Dutro, DOE/NV Waste Minimization Coordinator.

Co-Author

Angela P. Colarusso

U. S. Department of Energy/Nevada Operations Office

M/S 505, P. O. Box 98518

Las Vegas, NV 89193-8518

(P) (702) 295-1218/ (F) (702) 295-1153 